\title{
LECTURAS Y AUTOCONFIGURACIÓN: SYLVIA MOLLOY LECTORA DE VICTORIA OCAMPO
}

\author{
POR \\ MAYA GonzÁlez Roux \\ Universidad Nacional de La Plata - CONICET
}

Todo escritor se inscribe en su texto en el acto de leer, en una suerte de autorrepresentación oblicua. Una suerte de dime a quién lees (o a quién quieres que crea que lees) y sabré quién eres.

Sylvia Molloy, "Ficciones de la autobiografía" 67

¿Ambiciones literarias? ; Vaya si las tengo! ;Si supieras, mi querida, hasta dónde quisiera llegar, a quién querría igualar! Pero no conseguiré hacer nada en el campo de la novela. Tengo que escribir a bâtons rompus, cuando se me antoje, como se me antoje. Jamás podré crear un personaje. Lo llevaría a la rastra, y eso no sirve. Y todos mis personajes serían "yo" disfrazada. Perfectamente insoportable. ¿Cómo demonios puede uno deshacerse de su "yo"?

Victoria Ocampo, carta a Delfina Bunge del 29 de enero de 1908 (Autobiografia II 85)

La ficción y la crítica, declaraba Sylvia Molloy en referencia a sus dos actividades, conviven en ella en un delicado equilibrio que impide el sentimiento de escisión: “[...] mis dos escrituras -la de ficción y la de crítica- dependen mucho una de otra y se contaminan provechosamente" (Link, "Intermitencias"). Hablar de contaminación presupone otro término, el de fronteras. La obra de Molloy se sitúa en la frontera en la medida en que existe una zona de contacto, de pasaje, de contaminación entre las dos actividades que otorgan a su estética un carácter permeable: tempranamente Molloy eligió el camino del ensayo, a través de una vasta producción crítica, y sólo más tarde eligió la escritura de ficción. ${ }^{1}$ Esta permeabilidad entre las escrituras es un trazo que, sin

1 Se trata de dos novelas En breve cárcel (1981) y El común olvido (2002) y los libros de relatos cortos Varia imaginación (2003) y Desarticulaciones (2010). 
duda, se descubre en su figura de intelectual. En otras palabras, si en la escritura crítica de Molloy se entrevé una configuración de su identidad, en las lecturas y los ensayos se encontrarían los gérmenes de su ficción literaria. ¿De qué modo se configura esta identidad? ¿Cuál es su trazo sobresaliente?

Sin lugar a dudas, sus preocupaciones intelectuales están vinculadas con la enseñanza y con la crítica literaria, preocupaciones que a su vez se enriquecen por medio de la escritura de ficción. Se trata de escrituras que, al operar de modo conjunto, tejen y dan consistencia a su figura de escritora. Sin embargo, el carácter compuesto de su estética resulta no sólo de este cruce de escrituras sino también de sus ensayos que enmascaran los rasgos de la escritora de ficción. En este sentido el ensayo es una suerte de laboratorio de escritura puesto que funciona como un lugar de experimentación -donde se prepara la ficción literaria- y de creación de "autorretratos oblicuos" en los que predominan ciertos rasgos de su propia experiencia como el bilingüismo, el cosmopolitismo y la doble nacionalidad (su padre era irlandés y su madre descendiente de franceses). Sus trabajos sobre el género autobiográfico manifiestan en especial esta tendencia hacia el autorretrato y esto es así porque en ellos Sylvia Molloy establece un sistema de lectura singular que, al mismo tiempo que revela, oculta: es decir, si el sistema revela el propio método de interpretación del texto autobiográfico analizado, también la lectura configura y oculta la identidad de la escritora. ${ }^{2}$

A pesar de la diversidad de temas que la autora ha trabajado, cierto carácter marginal aparece de manera constante en sus lecturas críticas. Esto puede deberse al hecho de que los autores que aborda han experimentado cierto tipo de marginalidad, o bien porque la lectura que ella propone, al impulsar una interpretación contra canónica de autores consagrados, se realiza en "los márgenes". Este último tipo de marginalidad puede constatarse en su libro Acto de presencia. La escritura autobiográfica en Hispanoamérica, un conjunto de ensayos que, al poner en evidencia una manera de leer a contracorriente, no hace más que preparar el terreno hacia la escritura de ficción. De hecho pareciera que una escritura recubriese otra, como si por debajo de las lecturas de algunas autobiografías hispanoamericanas y de los cuestionamientos de Molloy,

2 Especialista en literatura latinoamericana, Sylvia Molloy abordó diversos temas a lo largo de los años a pesar de que la literatura de Borges siempre fue tutelar en sus reflexiones desde el temprano estudio Las letras de Borges (1979). Si en sus comienzos sus preocupaciones críticas se centraron en la recepción en Francia de la hispanoamericana (tema de su tesis doctoral), a lo largo de los años sus escritos se diversificaron hacia los efectos del exilio, como por ejemplo la relación entre el fenómeno del bilingüismo y la identidad, el trabajo con la memoria o también las "ficciones del regreso", tal como las definió. Una de sus preocupaciones fundamentales es la que versa sobre la autorrepresentación del sujeto en la escritura, campo donde encontramos sus textos sobre la autobiografía y la representación de la homosexualidad en la literatura, dos temas mayores sobre los cuales Molloy se ha convertido en un referente incuestionable en los estudios latinoamericanos.

Revista Iberoamericana, Vol. LXXXI, Núm. 250, Enero-Marzo 2015, 201-216 ISSN 0034-9631 (Impreso)

ISSN 2154-4794 (Electrónico) 
se entreviera a la escritora de ficción que traspasa la máscara de la crítica y profesora universitaria. ${ }^{3}$ Dicho de otro modo, leer desde los márgenes o desplazar los textos hacia los márgenes es una operación fecunda para su ficción literaria, concebida desde un pensamiento "de los márgenes". Algo de este orden sugería Molloy al referirse a la recepción argentina de su novela En breve cárcel. La crítica la había presentado como una autora "por fuera" del canon de la literatura argentina debido a las circunstancias biográficas: se trataba de una profesora universitaria que residía en los Estados Unidos y cuya novela había sido editada en España y no en Argentina. Estos tres elementos parecían no poder conformar la imagen del "escritor argentino", según deploró Molloy al rememorar aquella recepción (Molloy, "En breve cárcel: ...” 29).

Ahora bien, la propia autora, desautorizando ciertas lecturas, sostuvo que: "No me siento tentada, como le ha sucedido a más de un crítico al tratar el tema, a insinuar que el hecho de escribir sobre autobiografía sea, en sí, una forma de autobiografía." (Molloy, Acto de presencia 11). Sin embargo, y a pesar de que los ensayos de su libro Acto de presencia no revisten, como el efecto de un espejo, un carácter autobiográfico, admiten ser leídos como oblicuamente autobiográficos, para retomar los términos de la autora. De ahí que estos ensayos, cuya interrogación esencial se centra en cómo el autobiógrafo se inscribe en su texto, sean también una manera -oculta, disimulada, enmascarada- de pensar su propia identidad.

\section{De la alografía A la AUtobiografía}

El libro Acto de presencia puede considerarse fundacional en lo que concierne las reflexiones de Molloy sobre la autobiografía. Al volver sobre su paradigma de lectura, debemos retener los estudios teóricos de varios críticos, entre ellos los de Georges Gusdorf, Michel Foucault y Paul de Man, pilares en su teoría sobre la autobiografía, pero también la obra de Borges, figura central como ya se ha dicho. En líneas generales, Molloy adscribe a la teoría de Gusdorf según la cual la autobiografía tiende a manipular el pasado relatado. También atribuye un interés especial al vínculo entre la lectura y la escritura -es decir, la subjetivación de la escritura, tal como la analiza Foucault, esencial para la construcción del yo en la ficción-y adhiere a la perspectiva de Paul

3 El libro fue originariamente publicado en inglés en 1991 bajo el título At Face Value. Autobiographical Writing in Spanish America y traducido al español más tarde, en 1996. Gran parte de los textos que lo componen son una versión revisada de textos anteriores los cuales, sin embargo, no preceden a su primera ficción literaria, En breve cárcel. Pero esto no condiciona nuestra lectura pues no se trata aquí de comprender las dos escrituras en un plano cronológico - de hecho estos escritos críticos sobre la autobiografía no suponen un momento anterior a la literatura de ficción- sino de resaltar su carácter concomitante en la configuración de la identidad.

Revista Iberoamericana, Vol. LXXXI, Núm. 250, Enero-Marzo 2015, 201-216 ISSN 0034-9631 (Impreso)

ISSN 2154-4794 (Electrónico) 
de Man para quien la autobiografía es ante todo una construcción. En el paradigma de lectura de Molloy esta última corriente se vincula a la concepción de Borges sobre la identidad, concepción en la que tendremos que detenernos pues pone el acento en la referencia textual, esencial en lo que atañe a la interpretación del texto autobiográfico.

Recordemos que Paul de Man representa aquella corriente teórica que, al objetar toda diferencia entre la autobiografía y la ficción, se opone al pensamiento crítico que preconizaba la referencialidad del género autobiográfico. De este modo, es el texto y no su autor ni la historia, el foco de atención. Para de Man lo esencial de la autobiografía no reside en el conocimiento veraz que ella pueda ofrecer sobre una persona sino en que ella da cuenta de la imposibilidad de "totalización". Este término debe ser entendido en tanto que existencia de un sistema textual conformado por substituciones topológicas: el texto no puede constituirse como una "totalidad" del ser en la medida que es dictado por el lenguaje, el cual resulta insuficiente para captar el sentido total del ser. En otras palabras, a pesar de las herramientas que el lenguaje ofrece al autobiógrafo para relatar su vida, la "totalización" se revela imposible. De Man señala, entonces, que aquello que el escritor "realiza" por medio de la autobiografía está determinado por los recursos de su medio, es decir el lenguaje, y que por ello la mimesis que operaría en la autobiografía no es más que una figuración entre otras producida por la "estructura especular" del texto (de Man 71). De esta estructura especular deriva la noción central que propone, esto es el texto autobiográfico como una figura retórica, la prosopopeya, por medio de la cual la entidad ausente - muerta o sin voz- recibe el poder de la palabra. Gracias a la prosopopeya, la identidad del autobiógrafo no es referencial sino el resultado de un movimiento retórico: la prosopopeya es la máscara textual que anula la afasia al ofrecer una voz, un "yo", al pasado o a los muertos a través del lenguaje (de Man 76). De ahí que la autobiografía, para el crítico, se dedique a otorgar y a despojar las máscaras, a dar y a deformar los rostros. En otros términos, la autobiografía atañe a "las figuras, a la figuración y a la desfiguración" (de Man 80).

Esta noción del "yo" como máscara textual conduce a Borges y, a través de él, a la autoconfiguración de Molloy en su lectura. Recordemos el ensayo "La nadería de la personalidad" donde Borges negaba la preeminencia dada al "yo" al despojarlo de toda realidad para así afirmar su inexistencia como un todo. Allí Borges sostenía que "el yo es un punto cuya inmovilidad es eficaz para determinar por contraste la cargada fuga del tiempo. Esta opinión [de Shopenhauer] traduce el yo en una mera urgencia lógica, sin cualidades propias ni distinciones de individuo a individuo." (Borges, "La nadería de la personalidad" 104). En este sentido, algunos años antes -en 1922- en la famosa "Proclama" del número 21 de la revista Ultra, Borges escribía: "Todos quieren realizar obras apelmazadas i perennes. Todos viven en su autobiografía, todos creen en su personalidad, esa mezcolanza de percepciones entreveradas de salpicaduras de citas, de admiraciones provocadas i puntiaguda lirastenia." (Videla 200). Sin embargo, esta denuncia sobre la inexistencia del "yo", no impide a Borges postular que toda literatura

Revista Iberoamericana, Vol. LXXXI, Núm. 250, Enero-Marzo 2015, 201-216 ISSN 0034-9631 (Impreso)

ISSN 2154-4794 (Electrónico) 
es autobiográfica. ${ }^{4}$ Así también lo explicaba Enrique Pezzoni-en su ensayo "Fervor de Buenos Aires: autobiografia y autorretrato"-quien veía que el impulso autobiográfico aparece en el universo literario de Borges y, especialmente, en su poesía:

La veracidad del que habla en la poesía, la confidencia que transmite cada vez es para el joven Borges un pormenor anecdótico que se reitera: recomposición instantánea del "rígido" universo en la combinatoria metafórica, constitución del sujeto en esa reorganización y, a la vez, denuncia de la aventura imposible : constituirse o siquiera imaginarse como un Yo estable, continuo, permanente (Pezzoni 86, énfasis nuestro).

Personalidad, autobiografía y cita, estrechamente vinculadas para Borges, constituyen una tríada que Sylvia Molloy también emplea para abordar las preocupaciones autobiográficas del escritor que aparecen ya desde sus primeras escrituras. "Cita y autofiguración en la obra de Borges", texto que explora bajo el signo de la autobiografía la constitución del sujeto por medio de la lectura, viene a confirmar su posición según la cual toda empresa autobiográfica no puede más que conformarse a través del lenguaje, es decir, constituirse en términos de literatura. Esto significa que a través de sus lecturas, de las citas de textos y de autores, Borges logra componer un "museo textual" donde el "yo" puede afirmarse y, en esta afirmación, constituir su autorretrato:

Por la alografía [Borges] llega a la autobiografia. [...]. La ceremonial visita a estos muertos, a estos escritores cuyas obras ya son de todos, son visitas autorreflexivas, diálogo especular consigo mismo. [...]. La tarea de citar, de recordar los libros de otros, de conjeturar al otro que se vuelve yo mismo al ser citado [deviene] la felicidad de ser (Molloy, Las letras de Borges 235-236, énfasis nuestro). ${ }^{5}$

En el marco de la autoconfiguración de Sylvia Molloy a través de sus lecturas, la afirmación del comienzo resulta reveladora. Si la alografía es el camino para llegar a la autobiografía, ¿cómo están compuestos los “caminos alográficos” de Molloy, es decir, sus lecturas sobre la autobiografía?

4 En "Profesión de fe literaria", sostenía: "Éste es mi postulado: toda literatura es autobiográfica, finalmente. Todo es poético en cuanto nos confiesa un destino, en cuanto nos da una vislumbre de él. En la poesía lírica, este destino suele mantenerse inmóvil, alerta, pero bosquejado siempre por símbolos que se avienen con su idiosincrasia y que nos permiten rastrearlo. [...]. En las novelas es idéntico el caso. [...]; lo que afirmo es nuestra codicia de almas, de destinos, de idiosincrasias, codicia tan sabedora de lo que busca, que si las vidas fabulosas no le dan abasto, indaga amorosamente la del autor" (Borges, "Profesión de fe literaria" 143-144).

5 Molloy se refiere a las lecturas de Borges sobre Cervantes y Quevedo. "Los muertos" deben ser entendidos bajo la lógica del pensamiento de Paul de Man, lo que equivale a decir que las lecturas de Borges, tal como las inscripciones en las tumbas que citan a los muertos -en este caso Cervantes y Quevedo-devuelven la voz y el rostro a los dos escritores españoles.

Revista Iberoamericana, Vol. LXXXI, Núm. 250, Enero-Marzo 2015, 201-216 ISSN 0034-9631 (Impreso)

ISSN 2154-4794 (Electrónico) 


\section{LECTURAS DESPLAZADAS}

Entre las distintas autobiografías analizadas en Acto de presencia (de Domingo Faustino Sarmiento, Juan Francisco Manzano, María de las Mercedes Santa Cruz y Montalvo -más conocida como la condesa de Merlin-, Miguel Cané, Mariano Picón Salas, Norah Lange, Lucio V. Mansilla y José Vasconcelos), interesa detenerse en particular en el capítulo dedicado a Victoria Ocampo ya que en él se pone en evidencia una lectura contra canónica que incluso pareciera proyectar la figura de Ocampo hacia los márgenes de la literatura argentina. Nos interesa entonces observar las operaciones realizadas por su lectura en función de la imagen que Molloy desea configurar. En el caso de Ocampo, adelantemos que se produce un desplazamiento de su imagen, desde el lugar de autoridad intelectual dentro del campo argentino hacia el de la escritora que surge bajo el signo de lo ilegítimo.

La lectura de Molloy se concentra en los seis volúmenes de la autobiografía póstuma de Victoria Ocampo (publicados entre 1979 y 1984) y, en menor medida, en algunos pasajes de los Testimonios, diez volúmenes publicados entre 1934 y 1977. Ya desde el título del capítulo, "El teatro de la lectura: cuerpo y libro en Victoria Ocampo", la autora enmarca su perspectiva: el de las escenas de lectura que revelan la singularidad del "yo" que Ocampo configura y desea dar a conocer. La extraordinaria cantidad de libros mencionados en la autobiografía y, sobre todo, la representación del acto de lectura, son reveladoras para Molloy y le permiten comparar a Ocampo con la imagen de Hamlet quien se mostraba "con un libro entre las manos" (Molloy, Acto de presencia 79). Si bien las referencias literarias -es decir, qué leía o qué libros decía leer Ocampo-son esenciales para Molloy, su lectura crítica se enmarca en la problemática de la alteridad y para ello analiza esta autobiografía a partir de la naturaleza clandestina e ilícita que Ocampo mantenía con la literatura y en sus relaciones sentimentales. El retrato que dibuja revela a una Victoria hasta ahora desconocida: tímida y silenciosa, sobre todo delante de los interlocutores masculinos, ella no pudo -por prohibición familiar, es decir social- cumplir con su vocación de juventud, el de ser actriz. Esta imagen íntima se opone a la imagen pública que generalmente se tiene de ella, una oposición por momentos tan desconcertante que no es anodino preguntarse sobre el efecto que produce este desvío de la lectura de Molloy y también pensar que, tal vez, esta lectura construya una figura idealizada de Ocampo. Al tener en cuenta qué representaba Victoria en el campo cultural argentino, cómo la definía el ambiente intelectual y cómo se definía a sí misma - como portadora de una voz y de una opinión legítimas-, no es aventurado pensar en una idealización por parte de Molloy. Pero aquí hay que señalar que su propósito es precisamente el de idealizar la figura de Ocampo y que no advertir este aspecto equivaldría a empobrecer los efectos de ciertos desvíos y silencios que operan en su lectura. Por ello mismo, a partir de estos efectos de la lectura es posible

Revista Iberoamericana, Vol. LXXXI, Núm. 250, Enero-Marzo 2015, 201-216 ISSN 0034-9631 (Impreso)

ISSN 2154-4794 (Electrónico) 
sugerir un vínculo entre el retrato de Victoria Ocampo elaborado por Sylvia Molloy y su propio autorretrato.

Recordemos los valores aristocráticos con los que Victoria juzgaba y apreciaba la cultura argentina. Fascinada por Europa -sobre todo Francia e Inglaterra- y los Estados Unidos, Ocampo sostenía que la cultura argentina debía “absorber” las manifestaciones culturales europeas y familiarizarse con los movimientos artísticos extranjeros. Sin lugar a dudas, la tarea de introducción en Argentina de estos movimientos era el rol de la elite intelectual que proclamaba ser una suerte de médium. En el plano cultural, prevalecía entonces el criterio que miraba con atención lo que sucedía en el extranjero. Respecto a este punto, es de amplio conocimiento que la palabra de Ocampo antes que ser criticada era por sobre todo escuchada. ${ }^{6}$

Con respecto a la lectura de Sylvia Molloy, marcada por desviaciones y silencios, ésta busca subrayar el carácter teatral de las lecturas de Ocampo, es decir la puesta en escena del acto de lectura. Este carácter pondría en evidencia, por ejemplo, la preocupación de Victoria por la autorrepresentación y también el gusto por una vocación que, como se dijo más arriba, le fue prohibida, por supuesto por ser mujer. Su autobiografía es un testimonio del sentimiento que albergaba al sentirse a contracorriente de los "roles" acordados a las mujeres por la sociedad de su época, los cuales no correspondían al de actriz o escritora. En El imperio insular da cuenta de ello:

Literato es una palabra que sólo se toma en sentido peyorativo en nuestro medio. "Es un literato" (o peor aún "es una literata") significa un inservible, un descastado, [...]. Si se trata de una mujer, es indefectiblemente una bas-bleu, una poseuse, está al borde de la perversión, y en el mejor de los casos es una insoportable marisabidilla, mal entrazada. En cambio la palabra estanciero tiene prestigio (Ocampo, El imperio insular 104, el énfasis le pertenece).

Para Ocampo, al serle negada la posibilidad de ser actriz, la literatura se convierte en una forma vicaria del teatro ya que descubre en los libros la posibilidad de autorrepresentarse. Esto se pone en flagrante evidencia, según Molloy, en un episodio particular descrito por Victoria, cuando asiste a la representación de L'Aiglon de Rostand. Durante la obra, la fascinación de Victoria por el protagonista es tal que termina identificándose con él, de acuerdo a lo que escribe en sus Testimonios: “¿Por qué me reconocí? La cosa parece descabellada. El problema del hijo de Napoleón no era mío. Pero ese muchacho enfermo (la tisis galopante me pareció, entonces, un mal

6 En relación a ello, en una conferencia pronunciada en Italia en 1934, Victoria Ocampo afirmaba: "Para mí, la América del Sur se halla aún a tal punto mezclada a Europa, empapada de Europa -no obstante poseer un caracter propio, cuyos rasgos se acentúan cada día más-, que no es posible evocar a la una sin que la otra surja. Y hay pocos temas americanos en que Europa no se deslice por algún resquicio" (Ocampo, Testimonios 187).

Revista Iberoamericana, Vol. LXXXI, Núm. 250, Enero-Marzo 2015, 201-216 ISSN 0034-9631 (Impreso)

ISSN 2154-4794 (Electrónico) 
envidiable) estaba preso en Schoenbrunn, como yo en Florida y Viamonte" (Molloy, Acto de presencia 82). Recordemos que, prisionero, el protagonista recibe algunos libros clandestinamente lo que convierte su lectura en una práctica furtiva: "En esta ilegalidad, asumida desafiantemente como acto de liberación, Ocampo reconoce la marca de su propia lectura" (Molloy, Acto de presencia 84). Este episodio es doblemente revelador en cuanto la identificación de Victoria se convierte en un proceso complejo de traducción en varios niveles:

\begin{abstract}
Si la lectura es representación, esta particular lectura de L'Aiglon es la representación de una representación. Y también es, por supuesto, una traducción : no sólo un traslado de lo textual a lo vital, o de la convención teatral francesa a la cotidianeidad argentina, sino de un género sexual a la representación del otro : la joven Ocampo se identifica con un varón pero también con una mujer que representa a un varón (Molloy, Acto de presencia 85$)$.
\end{abstract}

La alteridad, señalada aquí en términos de traducción, reaparece en la preocupación por el espacio y la visibilidad de la mujer -tema que Molloy retomará, pero con otro sentido, en el capítulo sobre Norah Lange en el libro Acto de presencia. En lo que concierne el teatro y la literatura, aquello que le era permitido o prohibido a la mujer respondía de modo claro a la división existente entre el espacio público y el espacio privado. Así, las representaciones teatrales, alejadas de la mirada pública, quedaban limitas al dominio privado, lo que permitía proteger a la mujer de toda exposición juzgada como poco digna (Molloy, Acto de presencia 86). En este sentido, el caso de Victoria Ocampo no deja de asombrar pues, como es conocido, se convirtió en uno de los personajes públicos más importantes e influyentes del mundo intelectual de su época, llegando incluso a fundar en 1936 la "Unión Argentina de Mujeres", independientemente de la célebre revista Sur aparecida en el año 1931. Además, no es de extrañar que el convertirse en escritora a pesar de su vocación teatral haya dejado marcas en la escritura: como sostiene Molloy, "la escritora es siempre una actriz enmascarada que representa un rôle manqué" (Molloy, Acto de presencia 89, el énfasis le pertenece). Esto recuerda el caso de la propia Molloy quien en su texto "En breve cárcel: pensar otra novela" señalaba las dificultades que le impidieron ser considerada como una "escritora argentina". En este sentido, y a partir de la explicación que ofrece sobre Victoria Ocampo, no es aventurado preguntarse si la propia Sylvia Molloy no representa también un "rôle manqué" en sus escritos críticos. ¿No cabría pensar que bajo la lectura de la autobiografía de Victoria Ocampo, cuyo singular funcionamiento es el de revelar y ocultar al mismo tiempo que desplazar hacia los márgenes, se enmascara la escritora de ficción literaria?

Por otro lado, una parte importante del capítulo "El teatro de la lectura..." está consagrada a La rama de Salzburgo, tercer volumen de la autobiografía de Ocampo. Si la lectura de Molloy gravita en la "naturaleza ilícita" de la relación de Victoria con

Revista Iberoamericana, Vol. LXXXI, Núm. 250, Enero-Marzo 2015, 201-216 ISSN 0034-9631 (Impreso)

ISSN 2154-4794 (Electrónico) 
la literatura y con algunos hombres, precisamente La rama de Salzburgo es la obra que evidencia con mayor claridad el cruce entre la vida y la literatura. ${ }^{7} \mathrm{Al}$ focalizar la atención en el título - "Le rameau de Salzbourg", el capítulo seis de De l'amour de Stendhal-y en la figura de Francesca de Dante que Victoria toma como modelo para su configuración, Molloy busca poner el acento en la "naturaleza ilícita" de la relación secreta que mantiene con Julián Martínez, primo de su marido. El carácter "ilícito" de esta relación forma parte de una "transgresión general" de la vida de Victoria quien "inscribe sus tres pasiones prohibidas -el teatro, la literatura y el amor-en los márgenes de lo establecido" (Molloy, Acto de presencia 92). En este orden de cosas, llama la atención que la misma idea -el colocarse por fuera de lo establecido- aparece en un testimonio de Molloy al referirse a las escritoras que la marcaron -Katherine Mansfield, Colette y Carson McCullers-en quienes encuentra cierto carácter similar al señalado por Ocampo: la lectura de estas escritoras, asegura, la habría "condenado a lo transitorio y lo marginal" (Molloy, "Sentido de ausencias" 486). Los márgenes que lee en Ocampo, ¿no son acaso similares a los que ella evoca al revelar que su propia escritura se ha ido elaborando en los márgenes de otras escrituras, como si fuera una forma de cita o de comentario apócrifo? (Molloy, "Sentido de ausencias" 487). La misma pregunta se presenta al leer su ficción literaria, ¿o acaso el título En breve cárcel, tomado del soneto de Quevedo "Retrato de Lisi que traía en una sortija", ${ }^{8}$ no alude al amor confinado -el amor lésbico- a un espacio cerrado y destinado a ser condenado? Si tenemos en cuenta la lectura sobre Ocampo, resulta revelador que en esta primera ficción de Molloy las pasiones, la escritura y el amor, también se inscriben y elaboran a partir de un lugar que representa la condena de aquello que es juzgado como "ilícito".

En la misma lógica, y siempre bajo la misma "naturaleza ilícita" de los vínculos con lo literario, se evidencia otro entrecruzamiento entre Victoria Ocampo y Sylvia Molloy. En el texto "Sentido de ausencias", donde configura su genealogía literaria, Molloy se libra a reconstruir sus primeras lecturas de la infancia. La escena de lectura que recrea, muy similar a lo que observa en Victoria Ocampo, es por ello mismo muy elocuente. Al recordar la lectura de un libro en inglés de cuentos de hadas, se detiene en la "mirada

\footnotetext{
"Lo vivido y lo leído forman un sistema de vasos comunicantes, se traducen recíprocamente. [...]; lo que importa es que el contacto, la mezcla, y el refuerzo mutuo entre las dos -vida y literatura-son incesantes" (Molloy, Acto de presencia 90-91). Aquí la autora retoma una declaración de Ocampo durante una entrevista con Fryda Schultz de Mantovani, aparecida en un volumen de sus Testimonios, que merece la pena citar: "En mi infancia, adolescencia y primer chapuzón en la juventud, yo vivía en los libros lo que no podía vivir en la vida. Porque la vida estaba llena de tabúes absurdos para una niña o muchacha en los años en que me tocó serlo. Después yo viví en la vida lo que antes vivía en la literatura; y la literatura palideció. Quedaba para contar, de manera más o menos indirecta o directa, lo vivido" (Molloy, Acto de presencia 91 ).

8 "En breve cárcel traigo aprisionado,/ Con toda su familia de oro ardiente,/ El cerco de la luz resplandeciente,/ Y grande imperio del amor cerrado" (Molloy, En breve cárcel 9).
}

Revista Iberoamericana, Vol. LXXXI, Núm. 250, Enero-Marzo 2015, 201-216 ISSN 0034-9631 (Impreso)

ISSN 2154-4794 (Electrónico) 
tutelar" de una tía que seguía con minuciosidad su lectura ("Mi tía puntuaba mi lectura con comentarios de desaprobación ante ciertas violencias: los ingleses no sabían lo que eran las hadas" -Molloy, "Sentido de ausencias" 484). La descripción que ofrece, particularmente el peso de la mirada y la violencia que la niña siente, constituye la primera escena de lectura que deja la marca de un acto "ilícito" en su memoria, una marca que se repetirá más tarde para convertirse en epíteto de su propia práctica de escritura.

Por otro lado, al observar la lectura de la autobiografía de Victoria Ocampo a partir del vínculo con lo literario, sin lugar a dudas las referencias literarias merecen especial atención. Los eslabones de la lectura de Molloy, que se teje alrededor de varias reflexiones acerca de la dimensión literaria, están elaborados por distintas referencias: se trata principalmente de los intertextos de Stendhal y de Dante, éste por medio de la presencia de Francesca, pero también hay una gran acumulación de referencias literarias, Proust, Shakespeare, Eliot, entre otros autores, todos asociados a esa pasión no legítima que siente Victoria. De ahí entonces la afirmación de Molloy, según la cual "Ocampo piensa y siente "en literatura" puesto que comprende mejor su pasado gracias a sus lecturas, como por ejemplo las de Proust que le permitieron nombrar la fuente del fracaso de su relación con Julián Martínez (Molloy, Acto de presencia 96). Es decir, gracias a la literatura Ocampo logra poner en palabras la experiencia vivida. Pero quien tiene un rol aún más sobresaliente es la figura de Francesca: “[...] Ocampo se lee a sí misma en una figura [la de Francesca] que lee y para quien la lectura está aliada con lo prohibido. Más importante aún, se lee a sí misma en una figura que reflexiona sobre los efectos del proceso de lectura" (Molloy, Acto de presencia 93, énfasis nuestro).

La forma del trayecto de la lectura se descubre pues así como Victoria Ocampo se configura a través del personaje de Francesca, Molloy decide detenerse en una figura que elige, por voluntad propia y en razón de su época, cristalizar su propia imagen de escritora en los márgenes de lo permitido. Por ello la lectura marginal de Molloy, al situarse en clara oposición a aquello que Ocampo representaba en tanto que figura central al interior del campo cultural argentino, reenvía a la lectura que ella hace de sí misma al momento de considerar la recepción de En breve cárcel. En otros términos, al analizar la escritura de Victoria Ocampo, Molloy reflexiona al mismo tiempo sobre su propia escritura elaborada desde una marginalidad necesaria, según sus palabras, para pensar también toda literatura creada a partir de un "lugar desplazado" y silenciada por los grandes discursos. En este punto de la reflexión, es importante subrayar que el hecho de elegir la figura de Victoria Ocampo y de proponer una lectura basada en la cuestión de "la diferencia" - esto es, el carácter ilícito de las lecturas de Ocampo-, le permiten pensar su propia diferencia, no en términos biográficos sino en términos de literatura. Es decir, ella se lee en la figura de Victoria que ella misma ha creado y, en este gesto, se dibuja un diálogo entre su ficción -particularmente En breve cárcel-y su escritura crítica. A partir de este diálogo entre ambas escrituras no sorprende que la siguiente

Revista Iberoamericana, Vol. LXXXI, Núm. 250, Enero-Marzo 2015, 201-216 ISSN 0034-9631 (Impreso)

ISSN 2154-4794 (Electrónico) 
declaración, a pesar de referirse al propio lugar de Molloy, se aproxime también al caso de Victoria, o al menos a aquello que la lectura de Molloy quiere hacernos creer: "ese lugar desplazado [...], era mi lugar, donde podía por fin pensar la escritura (otra escritura), pensar la sexualidad (otra sexualidad), y hacer obra de ficción" (Molloy, "En breve cárcel" 32).

Asimismo, sin por ello disminuir el carácter polémico y transgresivo de la figura de Ocampo, señalemos que sus palabras y sus actos estaban respaldados por su apellido, célebre por su capital simbólico y cultural. ${ }^{9} \mathrm{El}$ apéndice del segundo volumen de su autobiografía, El imperio insular, es elocuente: compuesto principalmente de cartas y tarjetas postales - predominan las de Domingo F. Sarmiento, Nicolás Avellaneda, Carlos Pellegrini, Julio A. Roca y Bartolomé Mitre-, dirigidas a distintos miembros de la familia Ocampo -incluso Victoria decide incluir el acta de nacimiento de una tía abuela-, el apéndice tiene como fin ilustrar los orígenes de la "dama de letras", unidos a la historia y al futuro de la Argentina (Ocampo, Autobiografía II 183-208).

Consideremos una vez más el desplazamiento de la imagen de Victoria Ocampo, de autoridad intelectual hacia el espacio de lo ilícito. Conviene para ello detenerse en un breve comentario de Molloy acerca de la tapa de la edición de La rama de Salzburgo. $\mathrm{Al}$ tratarse de una publicación póstuma es difícil saber con certeza si Ocampo pudo haber participado o no en la elección de las imágenes, elección que, de modo certero, busca inducir la lectura hacia un sentido particular. ${ }^{10}$ Molloy revela la diferencia entre la cubierta de La rama de Salzburgo, un retrato de la figura de Victoria, y las cubiertas de los otros volúmenes, constituidos por fotografías. Describe así el retrato:

Mientras que hay fotografías en la tapa de los otros, en éste hay un impresionante retrato de cuerpo entero: una Ocampo sensual y físicamente desafiante, el cuerpo manifestándose de manera conspicua, con un libro en la mano. Es éste el retrato de Dagnan Bouveret mencionado con anterioridad, del que se borró el busto de Dante [...]. En cierto sentido esta portada, construida alrededor de la ausencia de Dante, vuelve esa ausencia en una presencia, y re-presenta a Francesca: el cuadro une el cuerpo del amor con el cuerpo

9 La familia Ocampo, como es de amplio conocimiento, es una de las más tradicionales de la Argentina. Resulta interesante observar hasta qué punto Victoria era consciente de ello y cómo arraigaba su genealogía a la historia del país, por ejemplo al rememorar uno de los primeros números de Sur: "En el segundo número de Sur iba un artículo sobre Martín Fierro. El autor de este poema gauchesco, nuestra Chanson de Roland, era primo de mi bisabuela materna" (Ocampo, "Visión de Jorge Luis Borges" 21).

${ }^{10}$ En este sentido, al comentar la edición de la Pléiade de À la recherche du temps perdu, Gérard Genette señalaba el vínculo entre el texto y la imagen como un caso extremo. Los retratos seleccionados de Proust, sin relación alguna con la cronología de redacción de $\grave{A}$ la recherche, impulsaban al lector a realizar un vínculo muy significativo "no tanto con la cronología de escritura de la obra sino con la cronología interna del relato, es decir la edad del héroe. Los tres retratos evocan entonces para el lector el envejecimiento de Proust al mismo tiempo que el del héroe-narrador, lo que conduce inevitablemente $\grave{A}$ la recherche hacia el estatuto de autobiografía" (Genette 37; traducción nuestra).

Revista Iberoamericana, Vol. LXXXI, Núm. 250, Enero-Marzo 2015, 201-216 ISSN 0034-9631 (Impreso) ISSN 2154-4794 (Electrónico) 
del libro, expresando de manera desafiante -como una actriz en el escenario-la unión de los dos (Molloy, Acto de presencia 94, el énfasis le pertenece).

No es de extrañar la importancia que Molloy otorga a la portada como creadora de sentido. No sólo delimita y vehicula una interpretación sino que, dado el tema que la autora analiza, la portada se convierte en una marca indeleble de la imagen que el autobiógrafo desea transmitir. Esta importancia también se observa en el cambio de la portada que la autora realiza para la segunda edición de su novela En breve cárcel en la que la pintura "Lectura de una carta" de Jan Vermeer Van Delft reemplaza a la de Miguel Ángel, "Mujer arrodillada con los instrumentos de la Pasión", de la primera edición. Los trazos sobresalientes de la pintura de Miguel Ángel muestran el perfil del cuerpo entero de una mujer, arrodillada y desnuda. A pesar de su desnudez, la mujer no revela ningún carácter femenino, salvo su rostro, de lo que resulta un cuerpo asexuado. Entre sus manos sostiene una corona de espinas que ella observa. La ligereza de su cuerpo desnudo contrasta con su cabeza cubierta por lo que parece ser una larga y densa trenza. En su conjunto, la desnudez del cuerpo y la corona de espinas contrastan con la otra pintura, la de Vermeer, que presenta a una joven dama burguesa, de pie delante de una ventana abierta y con una carta entre sus manos que ella lee. Sylvia Molloy explicó este cambio de la portada en función del deseo de focalizar la escena de lectura que, en la pintura de Vermeer, se encuentra en gran parte oculta por una cortina (Molloy, "En breve cárcel:..." 31). La pintura elegida opera como una cita en la medida que convoca al lector, le da cita como diría Antoine Compagnon (Compagnon 13-45), para evocar un sentido preciso. En este caso, la escena de lectura de la pintura de Vermeer invita al lector a alejarse de una interpretación biográfica de la novela de Molloy, tal como fue leída por las críticas en su primera edición, y recuerda en consecuencia el carácter textual del libro en detrimento del atributo biográfico.

En lo que concierne el libro con el que Victoria Ocampo aparece en su retrato, objeto que Molloy subraya, éste se relaciona con la ausencia del busto de Dante ordenada por sus padres. ${ }^{11}$ Esta representación de Victoria tiene una similitud con la pintura de Vermeer

11 Molloy insiste sobre la importancia que tiene Dante para Ocampo. En diversas oportunidades -ya sea en su autobiografía o en los Testimonios-, Victoria manifiesta su admiración por el poeta. Por ejemplo, en la conferencia en Italia antes mencionada, "Supremacía del alma y de la sangre", Ocampo se refiere a Dante como su única influencia ("[un] italiano me ha acompañado a lo largo de toda mi vida. No puedo menos de pensar en él cuando pienso en Italia. El ha sido Italia para mí", Ocampo, Testimonios 186) y reconoce haber recibido ese "vital nutrimento" del que habla en el Paraíso. A su vez, las diversas menciones a Dante, aparecidas en La rama de Salzburgo, habrían funcionado como ejercicios de preparación de su primer libro, De Francesca a Beatrice, escrito en francés. Según Molloy este texto también es autobiográfico: "[el libro es una manera de] completar el significado del cuadro de Dagnan Bouveret, de exhibir, a través de lo que es ahora una triple mediación - un libro sobre otro libro en una lengua que no es la materna- aquello que la sociedad le niega: expresar su cuerpo y expresar su mente" (Molloy, Acto de presencia 94-95). Dagnan Bouveret fue el pintor encargado de realizar el retrato de Victoria quien relata

Revista Iberoamericana, Vol. LXXXI, Núm. 250, Enero-Marzo 2015, 201-216 
elegida por Molloy para su novela pues aquí la desnudez de la mujer, en la pintura de Miguel Ángel, fue reemplazada por una ausencia vedada-aquello que esconde la cortina corrida en la pintura de Vermeer-, tal como sucede con la ausencia/presencia de Dante en el retrato de Ocampo. Precisamente, en esta ausencia significativa -interpretada como un silencio- se cifra una representación marginal compartida por las dos: mientras que Molloy insiste en el hecho de que Ocampo se relaciona -o juega a representarse así, tal una actriz-con la "figura furtiva" de Francesca, mujer seducida por la lectura y marcada por su relación sentimental clandestina, ella misma decide también vincular su ficción al secreto, sugerido por aquello que queda oculto tras la cortina en la pintura de Vermeer.

Por último, lo "ilícito", más allá de los vínculos sentimentales y literarios de Victoria Ocampo, reaparece cuando Molloy se detiene a analizar la visibilidad de Victoria. En aquella época, todo acto o gesto que se producía "por fuera" de aquello permitido para la mujer era fácilmente percibido como "ilícito". Por ejemplo, el libro De Francesca a Beatrice, publicado en 1924, tuvo críticas desfavorables justamente por ser demasiado "exhibicionista". ${ }^{12}$ Sin embargo, allí donde la crítica percibía una actitud a contracorriente de Victoria, Molloy leerá este gesto de otro modo. De acuerdo a ello, la presencia de Ocampo habría entonces sido diferente según las circunstancias, ya sea la mujer de letras, ya sea la mujer elocuente y fascinante que se permitía grandes extroversiones gracias a su posición social. Para decirlo de otro modo, la lectura de Molloy señala una vacilación en el modo de presentarse de Victoria pues, a pesar de su imagen imponente que suscitaba admiración entre sus amigos, en la escritura autobiográfica se presenta como privada de voz frente a sus interlocutores, la mayoría hombres siempre locuaces. Cabría entonces pensar que en los Testimonios Ocampo se muestra propensa al silencio para favorecer, paradójicamente, su propia voz: "[En los Testimonios] la tendencia de Ocampo al silencio es reemplazada por las voces de otros, voces que se habrán de volver, a medida que las escribe, su propia voz" (Molloy, Acto de presencia $100-101) .{ }^{13}$

una anécdota sobre este episodio en La rama de Salzburgo y en el volumen anterior, El imperio insular (Ocampo, Autobiografia II 151), episodio que Molloy también comenta (Acto de presencia 88). Durante uno de estos encuentros en los que la joven posaba, conociendo su admiración hacia Dante, Bouveret le propuso agregar el busto del poeta italiano. Sin embargo, ante la negativa de los padres - ese adorno no era conveniente para una mujer tan joven y podría juzgarse como un gesto pretensioso-, el busto fue retirado de la pintura.

12 En La rama de Salzburgo Victoria Ocampo comenta las críticas a su obra de Paul Groussac y Ángel de Estrada, para quienes develar el pensamiento -como sucedía en De Francesca a Beatrice- equivalía a develar el cuerpo. Como explica Molloy, ésta era la opinión general de la época acerca de las escritoras (Molloy, Acto de presencia 97). En este momento de su análisis, toma una posición clara en contra de las lecturas "esencialistas de lo femenino", que tienden a asociar la escritura femenina a una cuestión psicológica, y también en contra de las lecturas que escinden el cuerpo de la mujer de su escritura, esto es que consagran a la mujer en detrimento de la escritura.

13 Es necesario señalar una diferencia entre la autobiografía y los testimonios de Victoria Ocampo. Se trata de dos modalidades diferentes de escritura: mientras que la primera es una suerte de diario íntimo que

Revista Iberoamericana, Vol. LXXXI, Núm. 250, Enero-Marzo 2015, 201-216 ISSN 0034-9631 (Impreso)

ISSN 2154-4794 (Electrónico) 
El silencio se convierte así en un dispositivo esencial para su configuración, dispositivo que no oculta ningún secreto sino que, al contrario, tiende a otorgar una voz.

¿Por qué Molloy lee esta autobiografía con una mirada atenta hacia el silencio? Este es fundamental en la medida que está relacionado con la alteridad de la voz. Pues si por un lado favorece la creación de una voz, la de Victoria Ocampo, por el otro el silencio revela, de modo oblicuo, el vínculo de Ocampo con las otras voces, las femeninas, raramente citadas por ella. Con este último silencio Victoria se propone presentarse sola, como también lo observa Molloy en su lectura de Domingo F. Sarmiento, para poder mostrarse como "la" escritora. A través del doble silencio que opera en la escritura de Victoria -aquél que le es propio en vista de la apropiación de las otras voces, apropiación posible a través de la cita, y el silencio de las voces femeninas- Molloy muestra la inserción de Ocampo en el "sistema masculino", el único que tendría a su disposición. En lugar de ver allí una contradicción de Victoria -se define por medio de un sistema masculino al tiempo que desea escribir como mujer-, Molloy lee una marca de su genio: "Careciendo de voz propia y de un sistema femenino de representación, se apropia de voces canónicas masculinas y, por el mero hecho de enunciarlas desde un yo femenino, logra, como Pierre Menard cuando reescribe a Cervantes, diferenciar su texto" (Molloy, Acto de presencia 105, el subrayado le pertenece). Es decir, Ocampo logra componer su voz por medio de las lecturas masculinas, al mismo tiempo que conserva su alteridad, la de su propia voz. Al leer diferentemente, ella "desfamiliariza" el texto conocido, operación que Molloy denomina "la alteridad de la configuración autobiográfica". Esta afirmación permite una última constatación que entrecruza, una vez más, la figura de Ocampo con la de Molloy: las dos leyeron de modo diferente -la primera los textos canónicos masculinos, la segunda una figura canónica- y las dos lograron, en consecuencia, introducir su propia alteridad. Si la lectura y la escritura están íntimamente unidas en la autoconfiguración y si Ocampo logró conservar e inscribir su diferencia, Molloy viene entonces a dilucidar las escrituras de aquélla, logrando por consiguiente su propia configuración en tanto lectora de la diferencia.

reúne incluso cartas enviadas por ella misma o tarjetas postales recibidas, los testimonios discurren sobre escritores e intelectuales o temas específicos como los derechos de la mujer y sus responsabilidades, la literatura, la guerra, el continente americano. Si bien entre los testimonios hay algunas cartas, se trata sobre todo de textos destinados a la presentación de algunas figuras públicas o bien de conferencias. En otros términos, se trata de otro tipo de silencio - para retomar el término utilizado por Molloy- ya que los testimonios parecen tener por sobre todo una finalidad pública. De este modo, en la intimidad de su autobiografía, Ocampo puede permitirse el siguiente comentario, difícil de insertar en los Testimonios: "Las lecciones de español me aburrían porque las lecturas y la Historia Argentina me aburrían. Tampoco me interesaba la historia (tan apasionante y dramática) del descubrimiento y conquista de América. [...]. No simpatizaba con el espíritu de la Conquista o el de los conquistadores españoles. [...]. Que los indios americanos se los comieron vivos a estos personajes, se me importaba un pepino. Tampoco me atraían particularmente los diaguitas, los charrúas, los guaraníes, los comechingones, la indiada antropófaga. Colón nos había metido en un brete" (Ocampo, Autobiografia II 57).

Revista Iberoamericana, Vol. LXXXI, Núm. 250, Enero-Marzo 2015, 201-216 


\section{EL LECTOR DESENMASCARADO}

Entre las distintas singularidades de la autobiografía hispanoamericana, apuntadas por Sylvia Molloy a lo largo de su estudio crítico, una en particular requiere una particular atención. Se trata de la exhibición a la cual se somete el autobiógrafo. Así lo señala:

La autobiografía es una forma de exhibición que solicita ser comprendida, más aún, perdonada. Que me perdonen la vida : más de un autobiógrafo hispanoamericano haría suya la frase con que Victoria Ocampo cifra su actitud ante el lector. La expresión ha de leerse en su doble sentido. Literalmente, que se perdone al autobiógrafo, que se lea su vida con simpatía. Pero también, de modo más drástico, que se lo perdone como se perdona a un condenado, que se posponga su ejecución. La idea de transgresión evocada por la frase y el poder que en apariencia da al lector para que conceda un indulto, son frecuentes en estos textos. Hay a menudo [...] la sospecha de que, dada la condición incierta del género, quizá se lo esté enfocando de modo equivocado (Molloy, Acto de presencia 17, el énfasis le pertenece).

A su vez, cabría agregar que todo género literario ofrece cierta protección al escritor. Si esto es así, y ante la fragilidad de la autobiografía hispanoamericana durante el período estudiado por Molloy, el escritor se vería tentado a solicitar cierta indulgencia para su texto. Pero en la reflexión de la autora interesa subrayar el término "exhibición" pues comprender bajo este sentido la autobiografía supone que la imagen que ella ofrece es una representación y, además, que hay algo velado que el texto está desenmascarando. Pero hay más pues si escribir una autobiografía presume un grado de exhibición de parte del escritor, es posible que la operación inversa-leer y escribir acerca de este género- se convierta en una práctica signada no sólo por la exhibición sino también por la "máscara", término en resonancia con la teoría de Paul de Man evocada al comienzo. Exhibición y máscara son las dos operaciones de la lectura de Molloy cuyo funcionamiento revela entonces una práctica específica propensa a cierta marginalidad, característica que le permite leer autores no canónicos - tal el caso del chileno Augusto D'Halmar-al tiempo que sella la interpretación contra canónica de autores como Sarmiento y Ocampo entre otros. Molloy lee como el lector inventado por Borges cuya clave, de acuerdo a Piglia, es la libertad y todavía más: "Una de las claves de ese lector inventado por Borges es la libertad en el uso de los textos, la disposición a leer según su interés y su necesidad. Cierta arbitrariedad, cierta inclinación deliberada a leer mal, a leer fuera de lugar, a relacionar series imposibles" (Piglia 28; énfasis nuestro). De esta libertad de la lectura o, mejor aún, desviación de la lectura, el retrato de Ocampo libra una posible configuración de Molloy. O, como sostuvo ella misma respecto a Borges, por el camino de la alografía Molloy llega a la autobiografía.

Revista Iberoamericana, Vol. LXXXI, Núm. 250, Enero-Marzo 2015, 201-216 ISSN 0034-9631 (Impreso)

ISSN 2154-4794 (Electrónico) 
BiBLIOGRAFÍA

Borges, Jorge Luis. "La nadería de la personalidad". Inquisiciones. Madrid: Alianza Editorial, 2008. 92-104.

"Profesión de fe literaria". El tamaño de mi esperanza. Madrid: Alianza Editorial, 2008. 142-149.

Compagnon, Antoine. La seconde main ou le travail de la citation. Paris: Éditions du Seuil, 1979.

de Man, Paul. "Autobiography As De-Facement." The Rhetoric of Romanticism. New York: Columbia UP, 1984. 67-81.

Foucault, Michel. “L'écriture de soi”. Corps écrit 5 (1983): 3-23.

Genette, Gérard. Seuils. Paris: Éditions du Seuil, 1987.

Gusdorf, Georges. "Conditions et limites de l'autobiographie”. Formen der Selbstdarstellung. Analekten zu einer Geschichte des literarischen Selbsportraits. Festgabefur Fritz Neubert. Günter Reichenkron y Erich Haase, eds. Berlín: Duncker \& Humblot, 1956. 105-123.

Link, Daniel. "Intermitencias". <http:/www.pagina12.com.ar/diario/suplementos/ libros>. (03/08/02).

Molloy, Sylvia. En breve cárcel. Barcelona: Seix Barral, 1981. "Sentido de ausencias". Revista Iberoamericana 132-133 (1985): 483-488. Acto de presencia. La escritura autobiográfica en Hispanoamérica. México: Fondo de Cultura Económica, 2001. "Ficciones de la autobiografía". Vuelta 253 (1997): 65-68. “En breve cárcel: pensar otra novela". Punto de Vista 62 (1998): 29-32. Las letras de Borges y otros ensayos. Rosario: Beatriz Viterbo Editora, 1999.

Ocampo, Victoria. "Visión de Jorge Luis Borges". Cuadernos del Congreso por la Libertad de la Cultura 55 (1961): 17-23. Autobiografia II. El imperio insular. Buenos Aires: Ediciones Revista Sur, 1980. Testimonios, $2^{\text {da }}$ Serie 1937-1940. Buenos Aires: Ediciones Fundación Sur, 1984.

Pezzoni, Enrique. El texto y sus voces. Buenos Aires: Eterna Cadencia, 2009.

Piglia, Ricardo. El último lector. Barcelona: Editorial Anagrama, 2005.

Videla, Gloria. El ultraísmo. Madrid: Gredos, 1963. 